NBER WORKING PAPER SERIES

\title{
JOB STABILITY IN THE \\ UNITED STATES
}

\author{
Francis X. Diebold \\ David Neumark \\ Daniel Polsky
}

Working Paper No. 4859

\section{NATIONAL BUREAU OF ECONOMIC RESEARCH \\ 1050 Massachusetts Avenue \\ Cambridge, MA 02138 \\ September 1994}

Craig Hakkio provided helpful comments but bears no responsibility for the outcome. We gratefully acknowledge support from the National Center on the Educational Quality of the Workforce, the National Science Foundation, the Sloan Foundation, and the University of Pennsylvania Research Foundation. This paper is part of NBER's research program in Labor Studies. Any opinions expressed are those of the authors and not those of the National Bureau of Economic Research.

(C) 1994 by Francis X. Diebold, David Neumark and Daniel Polsky. All rights reserved. Short sections of text, not to exceed two paragraphs, may be quoted without explicit permission provided that full credit, including $($ ) notice, is given to the source. 


\title{
JOB STABILITY IN THE \\ UNTTED STATES
}

\begin{abstract}
Two key attributes of a job are its wage and its duration. Much has been made of changes in the wage distribution in the 1980 s, but little attention has been given to job durations since Hall (1982). We fill this void by examining the temporal evolution of job retention rates in U.S. labor markets, using data assembled from the sequence of Current Population Survey job tenure supplements. In contrast to the distribution of wages, which clearly changed in the 1980 s, we find that job retention rates have remained stable.
\end{abstract}

Francis X. Diebold

Department of Economics

3718 Locust Walk

University of Pennsylvania

Philadelphia, PA 19104

and NBER

Daniel Polsky

Department of Economics

3718 Locust Walk

University of Pennsylvania

Philadelphia, PA 19104
David Neumark

Department of Economics

Marshall Hall

Michigan State University

East Lansing, MI 48824

and NBER 


\section{Introduction}

How stable are jobs in the U.S. economy? Has stability changed over time, and if so, what is the nature of the change and which groups have been most affected? Very little is known about these fundamental questions, because little previous research exists. ${ }^{1}$ This lack of research is particularly surprising in light of the fact that the wage and stability of a job are certainly two of its key attributes, and the distribution across workers of one of those attributes (the wage) has changed dramatically in the 1980 s and has been subject to intense scrutiny.

The plausibility of declining stability is suggested by the dramatic changes in the distribution of wages that occurred in the 1980s. The salient changes are the deterioration of the relative wages of young and less-educated workers, an end to the convergence of black and white wages, and a closing of the gender gap in wages (Bound and Freeman, 1992; Burtless, 1990; Murphy and Welch, 1992). Much research suggests that the bulk of these changes can be explained by changes in the relative demand for skilled workers (Berman, Bound and Griliches, 1993; Blackbum, Bloom and Freeman, 1990; Katz and Murphy, 1992). But there is also some work suggesting increased bifurcation of the U.S. labor market into "good jobs" and "bad jobs," with an associated disappearance of stable, relatively high-pay employment for the middle and lower-middle classes (Bluestone and Harrison, 1986, 1988). This view is also reinforced by innumerable media reports claiming to document increased job turbulence (for a review, see Marcotte, 1993). Finally, there is evidence that training has changed in ways that mirror changes in the wage distribution, with more-educated and more-experienced workers now

'Exceptions include Marcotte (1993) and Farber (1993). Marcotte examines PSID data for the 1970s and 1980s, while Farber examines layoffs and plant closings. There is also evidence consistent with some firms or industries relying increasingly on part-time or nonpermanent workers (Abraham, 1990; Belous, 1989), although this evidence does not address trends among random samples of workers. The research closest to ours is Swinnerton and Wial (1993), which was done contemporaneously and independently. 
receiving relatively more job training (Constantine and Neumark, 1994).

In this paper we examine directly the temporal evolution of job stability in U.S. labor markets. We use data assembled from the sequence of Current Population Survey (CPS) tenure supplements, which are issued periodically and ask workers how long they have been with their current employer or at their current job. In addition to the information collected from the supplements, we use demographic characteristics and other variables available from the general CPS administered to the same individuals.

Our empirical procedures for examining changes in job retention rates build on Hall's (1972, 1982) seminal work on estimating the distribution of eventual job tenure, and Ureta's (1992) extensions of Hall's work. At the same time, estimates of the distribution of eventual job tenure are problematic if the survival function is not stable, so our research potentially calls into question the assumptions and findings of that earlier work.

In Section 2, we discuss the data used, our procedure for estimating retention rates, and adjustments to remove the effects of heaping, rounding and business cycles. We present our estimates of retention rates in Section 3, both in the aggregate and disaggregated by age, race, sex, education, occupation, and current tenure. We conclude in Section 4.

\section{Data and Methods}

\section{Estimating Retention Rates}

A concept central to our approach is the $\mathrm{t}$-year retention rate, $\mathrm{R}(\mathrm{t})$, which gives the probability that workers with a particular level of tenure today will have an additional $t$ years of tenure $t$ years hence. The t-year retention rate may be defined for any subgroup of the population, such as demographic groups or workers with particular initial tenure levels. Denoting current tenure by $c$, and other characteristics by $x$, we write the t-year retention rate as 
$R_{x c}(t)$. We refer to a sequence of retention rates, $R_{x c}(t), t=1,2, \ldots$, as a survival function. The survival function provides a complete characterization of the probability distribution of eventual tenure. ${ }^{2}$ Because the survival function and the probability distribution of eventual tenure contain precisely the same information, analysis may be based on either. From this point on, we work exclusively with the survival function.

Hall (1982) uses the 1978 tenure supplement and concludes that expected U.S. job tenure is long, insignificantly different for blacks and whites, and significantly shorter for women. The estimation of tenure distributions is complicated because the CPS data capture "incomplete spells" (as would any non-retrospective data), that is, completed tenure-to-date for people's current jobs. Because of this, the distribution of eventual tenure cannot be observed, but only inferred by estimating the survival function for employment.

Hall's estimation of the survival function from a single tenure supplement (i.e., from a cross-section) requires two assumptions. The first assumption, which is particularly germane to our research, is that the employment survival function is stable over time. This assumption permits one to infer, for example, the probability that an employed 35 year-old with zero years of tenure will accumulate at least ten more years of tenure (the ten-year retention rate for 35 year-olds), from data on 45-year-olds with ten years of tenure at the same point in time. In particular, this probability is estimated as the ratio of the number of 45 -year-olds with ten years of tenure to the number of 35-year-olds with zero years of tenure.

As Ureta (1992) points out, estimation of the survival function from cross-sectional data also requires a second assumption, that the overall "arrival rate" (the number of workers

\footnotetext{
${ }^{2}$ The probability distribution of eventual tenure is obtained from the survival function as follows. For a given level of current tenure, let $P_{x c}(t)$ denote the probability that additional tenure is greater than or equal to $t$ years, but less than $t+1$ years. For short, we refer to $P_{x c}(t)$ as the probability of $t$ years of additional tenure. Clearly $P_{x c}(t)=R_{x c}(t)-R_{x c}(t+1)$.
} 
beginning new jobs) is constant. Hall corrects only for changes in arrivals due to cohort size variation, but Ureta emphasizes that this is insufficient, because the period for which Hall was estimating the distribution of eventual job tenure witnessed large changes in labor force participation rates of women and older men, changes that also affected the arrival rate. To see the nature of the problem, note that if current 35 year-olds have a higher participation rate than current 45 year-olds, then the ratio of employed 45 year-olds with ten years of tenure to employed 35 year-olds with zero years of tenure will understate the ten-year retention rate for this group.

Ureta develops a method of estimating the survival function that does not require stable participation rates. This method requires the use of multiple CPS tenure supplements to calculate historical retention rates. ${ }^{3.4}$ By linking a few supplements, Ureta is able to estimate historical one-year retention rates as the ratio of the number of individuals with $c+1$ years of tenure in year $j+1$ to the number of individuals with $c$ years of tenure in year $j$. Historical retention rates are independent of changes in arrival rates, because they are calculated from data on the same cohort at two points of time. To return to our previous example, the ratio of employed 45 year-olds with ten years of tenure in, say, 1983, to employed 35 year-olds with zero years of tenure in 1973 will not understate the ten-year retention rate for this group, even if participation rates are rising for this cohort, because none of the new labor market entrants

\footnotetext{
${ }^{3}$ Ureta uses CPS tenure supplements for 1978, 1981, and 1983, ignoring (although acknowledging) the change in the tenure question after 1981 that we discuss below.

${ }^{4}$ Hall notes that retention rates can also be calculated historically by stringing together tenure supplements. In fact, he compares some crude calculations of retention rates from cross-sectional and historical data. Because he is interested only in a qualitative characterization of the long-term nature of jobs in the U.S. economy, however, he does not focus on the differences that emerge from the two procedures, as both indicate the same qualitative characteristic of relatively long-term job attachment.
} 
(arrivals) between 1973 and 1983 can accumulate ten years of tenure by 1983.

However, like Hall, Ureta must assume a stable survival function, for two reasons. First, she estimates one-year retention rates using tenure supplements that are more than one year apar. Second, she uses the estimated one-year retention rates to estimate eventual tenure distributions.

Here we dispense with the assumption of a stable survival function. In fact, our goal is to assess whether the survival function is stable. As Ureta's work makes clear, we cannot simultaneously avoid this assumption while providing a complete characterization of eventual tenure distributions. But we can avoid the assumption by linking together a longer sequence of CPS tenure supplements, and using them to characterize tenure distributions based only on observed historical retention rates.

The basic t-year retention rate for workers with c years of tenure is calculated as the ratio of the number of workers with $t+c$ years of tenure in the tenure supplement $t$ years hence $\left(\mathrm{N}_{\mathbf{x}}{ }^{0+t}(\mathrm{t}+\mathrm{c})\right)$, to the number of workers with $\mathrm{c}$ years of tenure in the current tenure supplement $\left(\mathrm{N}_{\mathrm{x}}{ }^{0} \mathrm{c}\right)$ ), where the ' $0^{\prime}$ superscript refers to the current year's supplement. Formally,

$$
R_{x c}(t)=\frac{N_{x}^{0+1}(t+c)}{N_{x}^{0}(c)}
$$

Retention rates can be calculated for any subgroup consistently represented across surveys. We shall classify by age, sex, education, race, industry, occupation, and current tenure.

\section{Characteristics of the Samples}

CPS tenure supplements are available for 1973, 1978, 1981, 1983, 1987, and 1991.5

\footnotetext{
${ }^{5}$ Tenure supplernents were also carried out in 1963,1967, and 1969, but the micro-data from these supplements are apparently not available in machine-readable form.
} 
Conditional on any characteristic, we can compute the t-year retention rate for the span of years, t, between any two supplements. Unfortunately, however, the question's wording has changed over time. In 1973, 1978, and 1981, the question referred to time working at the present job or business, asking "When did ... start working at his present job or business?" In 1983, 1987, and 1991 the question referred to time working (continuously) for the present employer, asking "How long has ... been working continuously for his present employer (or as self-employed)?" There is no decisive way to determine whether or not respondents interpreted the questions differently. Thus, to be safe, we are careful to focus on changes in retention rates that are not influenced by changes in wording of the tenure question.

In the first panel of Table 1, we show the set of spans for which we can directly estimate retention rates (ignoring, for the moment, differences in the tenure question). The entries indicate the span, $t$, for which the retention rate can be estimated, and the year at the top of each column indicates the year from which all rates can be estimated. The span measures the number of years between the year at the top of each column to some future year for which a supplement is available. Thus, for example, the " 5 " in the upper-left-hand corner indicates that we can directly estimate the five-year retention rate for 1973 .

The second panel of Table 1 displays the retention rates that can be compared over time. Ignoring changes in the tenure question, we can compare changes in retention rates for four combinations of years and retention rates: changes in four-year retention rates from 1983 to 1987, changes in 5-year retention rates from 1973 to 1978 , changes in 8-year retention rates from 1973 to 1983 , and changes in ten-year retention rates from 1973 to 1981.

However, changes in the tenure question limit the usefulness of some comparisons. The most consistent comparison is that of four-year retention rates for 1983 and 1987 . This comparison uses data only from 1983 and afterwards, and hence relies on a consistent tenure 
question. Comparisons of the five- and eight-year retention rates are problematic, because the comparisons cannot be made with a consistent tenure question. For example, five-year retention rates for 1973 are based on the early tenure question for both 1973 and 1978, while five-year retention rates for 1978 are based on the early tenure question for 1978 , and the later tenure question for 1983. However, despite changes in the tenure question, a comparison of ten-year retention rates for 1973 and 1981 is possible. For each of these years, retention rates are based on the early tenure question in the initial year, and the later tenure question in the final year. Thus, while estimates of retention rates for either 1973 or 1981 may be biased because of the change in the question, we should nonetheless be able to accurately estimate the change in retention rates from 1973 to 1981 , as long as the estimated retention rates for each year are equally biased.

The retention rate estimates are based on ratios of counts of workers with various levels of current tenure from different CPS samples of the population. The universe we use is nonagricultural workers, currently working or with a job but not currently at work, aged 16 or older. Although the CPS is a random sample, non-response to the tenure supplement can vary across years (and in fact does so quite substantially), and can vary differently based on demographic or other characteristics. Thus, we have to control carefully for changes in the representation of different workers among respondents to the tenure supplement in order to obtain unbiased estimates of these counts. We use the standard CPS sample weight multiplied by the reciprocal of the response rate to the tenure question for each race-age-sex subgroup, with age grouped into five-year intervals. ${ }^{6}$

- The CPS sample weight is the reciprocal of the probability of being sampled, adjusted for non-interview and variation in the sampling of race-age-sex and residence subgroups. 


\section{Rounding and Heaping}

The empirical probability distributions of reported tenure for each of the six supplements are indicated by the bars in Figure 1. The rough shape of these distributions is the same in each of these six years, with the highest proportion reporting tenure in the range of $0-1$ year, and the proportion declining nearly monotonically in subsequent years. ${ }^{7}$ However, the empirical distributions reveal some other features.

First, for 1983, 1987, and 1991, the proportion reporting tenure of 1-2 years is lower than the proportion reporting tenure of 2-3 years. This almost surely arises because of the wording of the tenure question. In the 1983 and subsequent surveys, the tenure question asks how long a person has worked for the present employer. If the answer is less than one year, the respondent is queried as to length of tenure in months; otherwise the answer is recorded in years. This suggests that if a person has worked more than one-and-a-half years, he is likely to respond that he has been working for two years. So we might expect that approximately one-half of the respondents who have 12-24 months of tenure are coded as having two years of tenure, rather than one. In contrast, the pre-1983 survey asks for the year in which the spell of tenure began, so this problem does not arise. ${ }^{8}$ The empirical probability distributions are consistent with this rounding problem, as the proportion reporting tenure of 1-2 years in 1983, 1987, and 1991 is roughly one-half of the proportion reporting tenure of $1-2$ years in 1973, 1978, and 1981.9

\footnotetext{
7 Our convention is that when a tenure interval is specified, the first value is included in the interval and the second excluded. For example, 3-6 means $3 \leq$ tenure $<6$.

${ }^{8}$ For example, if a respondent to the January 1981 supplement began working one-and-ahalf years ago, he responds with 1980, and tenure will be coded as one year.

${ }^{9}$ Another apparent difference between the first three and the last three years is that for the former, the spike at 0-1 years is larger. This may be attributable to the wording of the tenure question. Individuals may regard themselves as having changed jobs, but not employers, which would put more mass at low levels of tenure defined for the job instead of
} 
A second feature of the empirical tenure distributions is that the 1983,1987, and 1991 distributions have spikes at $5,10,15,20,25$, and 30 years, to which we refer as "heaping." The problem was originally identified by Ureta (1992), and presumably arises because of rounding with regard to the number of years for which a respondent has worked for the present employer. In contrast, for the three earlier supplements, in which respondents reported the year they began the tenure spell, any such heaping is much less evident.

We "de-heap" the data by estimating a mixture model for reported tenure, which we then use to reallocate the heaped data. For this purpose (and only this purpose), we assume the true tenure distribution is Weibull, with survival function $\exp \left[-\left(\alpha t^{\prime}\right)^{\beta}\right]$, where $t^{\prime}$ denotes true tenure, and we assume further that individuals report true tenure with probability $\mathrm{p}$ and report the nearest multiple of five with probability (1-p). We expect rounding to be more severe the longer the true length of the tenure spell, so we allow $\mathrm{p}$ to depend linearly on reported tenure $\mathrm{t}$, so $\mathrm{p}=$ $\gamma+\delta t$, where we expect to find $\delta<0$

Under these assumptions, the reported tenure distribution differs from the true probability distribution for two reasons-heaping and sampling variation. We use the minimum chi-square method to estimate the parameters $\alpha, \beta, \gamma$, and $\delta$. First, we divide the possible values of reported tenure into $J$ cells, and then we find the values of the parameters that minimize

$$
\sum_{j=1}^{J} \frac{\left(O_{j}-E_{j}\right)^{2}}{E_{j}},
$$

where $O_{j}$ is the actual number of observations in the cell, and $E_{j}$ is the expected number of observations given the parameters. ${ }^{10}$

the employer.

${ }^{10}$ The cells used are $0,1-2,3-4,5,6-9,10,11-14,15,16-19,20$, and 21 or more. 
After estimating the parameters of the mixture model, we "de-heap" the data. For each multiple of five years for reported tenure, we calculate the probability that respondents have reported the truth, using the estimates of $\gamma$ and $\delta$. We then redistribute, to adjacent values of tenure, the number of respondents estimated to have rounded. The redistribution is in proportion to the percentage shortfall between the expected number of observations at each of the adjacent values based on the estimated Weibull distribution, and the expected number of observations based on the mixture of the Weibull distribution and the heaping mechanism."

We treat the problem of half-year rounding, discussed above, in a similar fashion, by assuming that independently of reported tenure (as long as it exceeds 12 months), individuals report true tenure with probability $\theta$ and report one year more than true tenure with probability $1-\theta$. We then shift reported tenure down by one year for the proportion estimated to have rounded up by one year. ${ }^{12}$

Business Cycles

Business cycles may influence estimates of retention rates as fluctuations in unemployment affect the probability of temination, independently of underlying changes in job

"Because the tendency to round appears to be approximately three times more likely at multiples of five ending in zero than multiples ending in five, we use the following adjacent values. For multiples ending in five, we define the adjacent values as one year less or one year more of tenure (e.g., for five years of tenure, we use four and six). For multiples ending in ten, we define the adjacent values as one to three years less, and one to three years more.

${ }^{12}$ We estimated the mixture model separately for each of the three years 1983,1987 , and 1991. The estimates of $\alpha$ ranged from .22 to .23 , while those of $\beta$ ranged from .73 to .80 . The estimates of $\gamma$ and $\delta$ were consistent with a very low probability of rounding at low levels of tenure, but a rising probability with tenure; the estimates of $\gamma$ ranged from .975 to .999 , and the estimates of $\delta$ were -.009 . Finally, the estimates of $\theta$ ranged from .35 to .44 , consistent with our conjecture that roughly one-half of respondents round reported tenure upward. 
retention rates. ${ }^{13}$ To correct for this potential bias, we attempt to adjust retention rates for cyclical fluctuations by, in effect, adding back cyclical job terminations.

Our proxy for the cyclical position of unemployment, $U_{\mathbf{x}}(\mathrm{m})$, is simply the residual from a regression of the monthly civilian unemployment rate on a nonlinear time trend. ${ }^{14}$ We do this separately for demographic subgroups, classifying by sex, race (white and black), and age (16-20 and $20+)$. Then we form $E_{x}(m)=1-U_{x}(m)$ and obtain the retention rate via

$$
R_{x c}^{*}(t)=\frac{N_{x}^{0+1}(t+c)}{N_{x}^{0}(c)}\left[\frac{1}{\left[E_{x}(1) E_{x}(2) \ldots E_{x}(12 t-1)\right]}\right]
$$

Clearly, if unemployment were always on trend (that is, $U_{x}(m)=0$ and $E_{x}(m)=1$ ), the adjustment factor would be unity, so no adjustment would be made. Otherwise, the adjustment lowers retention rates in booms and raises them in recessions, with the size of the adjustment depending on the average deviation of the unemployment rate from trend over the span.

To illustrate the potential influence of cyclical fluctuations on retention rate comparisons in the simplest possible setting, consider the following example of a pair of 1-month spans:

${ }^{13}$ In addition, variation in the unemployment rate could influence the retention rate of workers employed at any point in time, if unemployment is correlated with the quality of job matches. We do not explore this source of bias.

${ }^{14} \mathrm{~m}$ indexes time periods (months), as will become clear. 


\begin{tabular}{|c|c|c|c|c|}
\hline & \multicolumn{2}{|c|}{ Scenario 1} & \multicolumn{2}{|c|}{ Scenario 2} \\
\hline & (month 0) & (month 1) & (month 0) & (month \\
\hline$N_{x}(c)$ & 200 & & 200 & \\
\hline$N_{x}(1+c)$ & & 100 & & 80 \\
\hline$U_{x}$ & $5 \%$ & $0 \%$ & $5 \%$ & $20 \%$ \\
\hline $\mathrm{R}_{\mathrm{xc}}(1)$ & & & & \\
\hline $\mathrm{R}_{\mathrm{xc}}^{*}(1)$ & & & & \\
\hline
\end{tabular}

The unadjusted retention rates indicate that job stability is lower in Scenario 2 than in Scenario 1. But with cyclical unemployment at $20 \%$ in month 1 in Scenario 2, the $20 \%$ drop in retention is entirely attributable to the $20 \%$ increase in terminations caused by the cyclical downturn. The adjusted retention rate is computed as $(80 / 200)(1 / .8)=.50$. This is equivalent to the retention rate in Scenario 1, because it adds back terminations caused by cyclical unemployment.

\section{Results}

\section{Basic Results: Four-Year Retention Rates}

Table 2 reports four-year retention rates for 1983 and 1987, classified by initial tenure. The first two columns report results using unadjusted data. Retention rates decrease for workers with less than 6 years of tenure and increase for workers with more than 6 years; overall, the retention rate decreases from .57 to .56 . The third and fourth columns report retention rates estimated using de-heaped data; the results are qualitatively similar. Finally, the last two columns report retention rates estimated from de-heaped data, adjusted for business-cycle effects. Again, the results are qualitatively similar. ${ }^{\text {1s }}$

\footnotetext{
${ }^{15}$ Because the effects of business cycles appear to be minor, in the disaggregated results that follow we report results correcting for heaping and rounding only.
} 
Figures 2-A to 2-D provide a graphical display of changes in four-year retention rates for the same tenure subgroups, classified also by five-year age groups. ${ }^{16}$ The retention rates are displayed for 1983 and 1987 , along with $95 \%$ confidence intervals. ${ }^{17}$ Overall, retention rate pattems are very similar across the two spans. Closer scrutiny, however, reveals a few potential movements that might deserve mention. Figure 2-A, for those with $0-3$ years of tenure, reveals no consistent pattem of retention rate shifts, but Figure 2-B, for those with 3-6 years of tenure, reveals a decrease in the retention rate for workers up to age 40 . The evidence for workers with 6 or more years of tenure, in Figure 2-C, is mixed, depending on the age at which the retention rate is evaluated. Finally, the evidence for workers averaging over all levels of tenure, in Figure 2-D, reveals essentially no change, except for workers in their twenties, for whom retention rates fell. While the change in the retention rates for these workers seems small, it is nonetheless interesting that it shows up for the age group that has experienced the largest relative wage decreases.

Finally, in order to provide additional perspective, we transform our estimates of retention rates into estimates of expected job tenure, under the assumption that the survival function may shift across time spans but is otherwise stable (for example, actoss different

${ }^{16}$ Retention rates are not calculated for subgroups which, when weighted, represent fewer than 20,000 individuals.

${ }^{17}$ Confidence intervals are computed by exploiting the binomial structure of the underlying data. In particular, $R_{x c}(t) \stackrel{a}{\sim} N\left(R_{x t}^{0}(t), \frac{R_{x c}^{0}(t)\left(1-R_{x c}^{0}(t)\right)}{N}\right)$, where a superscript of 0 denotes the true population retention rate, and $\mathbf{N}$ is the number of observations in the initial year. Thus, an approximate $95 \%$ confidence interval is given by

$$
R_{x i}^{0}(t) \in R_{x i}(t) \pm 1.96\left(\frac{R_{x c}(t)\left(1-R_{x c}(t)\right)}{N}\right)^{1 / 2}
$$


workers). Using exponential survival functions, the drop in the average retention rate from the 1983-1987 span to the 1987-1991 span corresponds only to a small change in average job tenure, from 6.3 years to 5.9 years. ${ }^{18}$

\section{Classification by Demographic Groups}

In Table 3 we provide further evidence on changes in job retention rates, reporting estimated four-year retention rates for subgroups of workers for whom previous research has documented changes in relative wages. First, we provide retention rates for college graduates versus high school graduates and high school dropouts. Overall, the latter group experienced a slight drop in the retention rate, from .48 to .47 , while college graduates experienced an increase, from .58 to .59 . These results differ somewhat once we classify by tenure in the base year, with the biggest relative change occurring for those with six or more years of tenure. Blacks experienced larger drops in retention rates overall, and for each tenure group. Overall, retention rates fell slightly for both men and women. ${ }^{19}$

Figures 3-A to 3-D provide a more in-depth look at changes in retention rates by schooling group; they show the percent change in retention rates for each demographic group, by tenure, by age group. Because the sample sizes become rather small, the confidence intervals for these changes are rather wide. Thus, for example, looking at all tenure groups together, in Figure 3-D, while the point estimates indicate that retention rates for college graduates increased

${ }^{18}$ The exponential survivor function is $\mathrm{e}^{-\lambda t}$, for which expected duration is $1 / \lambda$. Our fouryear retention rate is an estimate of $e^{-4 \lambda}$. Thus, for example, the estimate of .51 in the last column of Table 2 implies an estimate of $\lambda$ of .17 , for which expected duration is 5.9.

${ }^{19}$ It may be surprising that four-year retention rates are not lower for women. Hall (1982) estimated that in 1978, men were 30 percent more likely to reach five or more years of tenure. However, Ureta's (1992) estimates that correct for changes in arrival rates imply that the correct figure is 22 percent. Also, neither of these estimates fully captures the increased attachment to the labor force of women who entered in the 1980 s (e.g., Light and Ureta, 1992). 
relative to high school graduates and dropouts for workers through age 55, the increase is not statistically significant for any age group. Figures 3-B and 3-C, for workers with 3-6 and 6+ years of tenure, respectively, suggest the same qualitative conclusion. In Figure 3-C the increase is statistically significant for workers aged 26-35.

Figures 4-A to 4-D provide similar information for blacks and whites. In all cases, the point estimates indicate that retention rates for whites increased somewhat relative to those for blacks, except for the oldest workers. But given the small sample sizes for blacks, the increases are never statistically significant.

Classification by Industry and Occupation

We now turn to estimates of retention rates classified by characteristics of jobs, rather than characteristics of workers, as shown in Table 4. The relative decline in blue-collar, manufacturing jobs is frequently bemoaned as heralding the disappearance of stable, high-paying jobs for less-educated workers (Bluestone and Harrison, 1986 and 1988). This classification by industry and occupation provides evidence on the relative stability of alternative jobs, and it is useful for assessing whether changes in the industrial and occupational composition of the workforce can explain the decreases in retention rates (however small) that have been documented in some of the previous figures.

The overall retention rate increased by .02 in the goods-producing sector and fell by .06 in the service-producing sector. In addition, retention rates were, and still are, higher in the service-producing than in the goods-producing industries, suggesting that shifts away from goods-producing jobs do not lead to less stable jobs. Next, the retention rates classified by bluecollar and white-collar/service workers reveal that retention rates are generally slightly lower for less-tenured workers in white-collar and service occupations, although this relationship is reversed for more-tenured workers. Overall, however, retention rates are higher for white-collar 
and service occupations, and decrease only for blue-collar occupations.

In the following rows of Table 4, we classify by subgroups of white-collar and service occupations. Not surprisingly, retention rates are highest for professional and technical workers, and are lower by a substantial amount for clerical workers, and lower still for service workers. Furthermore, while retention rates on average increase slightly for professional and technical workers, they decrease slightly for the other occupations. Finally, for 1983-1987, the retention rate in service occupations is lower than that in blue-collar occupations, suggesting that workers who moved from blue-collar to service jobs may have entered less stable jobs. On the other hand, by 1987-1991, the retention rate in blue-collar occupations had nearly fallen to that in service occupations.

\section{A Longer-Term View: Ten-Year Retention Rates}

To this point, all our results refer to four-year retention rates for the spans 1983-1987 and 1987-1991. We devote most of our attention to these spans because they can be calculated and compared using a consistent job tenure question, as explained in Section 2. However, we also argued that ten-year retention rates for 1973-1983 and 1981-1991 could be compared meaningfully, because for each of these spans we begin with the first form of the tenure question and end with the second. Thus, at a minimum, we should be able to compare meaningfully the changes in ten-year retention rates.

Table 5 reports ten-year retention rates, which parallel those in Table 2 for four-year retention rates. For all tenure groups, not surprisingly, the estimated ten-year retention rates are considerably lower than the four-year retention rates. Interestingly, however, ten-year retention rates increase slightly for all tenure groups; the average increase over all workers is .01 . Thus, in contrast to the point estimates of four-year retention rates for the 1980s, which suggest slightly declining job stability, the point estimates of ten-year retention rates for the 1970 s and 
1980s suggest slightly rising job stability. The differences across four- and ten-year spans may occur either because four- and ten-year retention rates changed differently, or because the 1970s were different from the 1980 s.

Figures 5-A to 5-D provide a more in-depth view, classifying by age as well. For workers with 0-3 and 3-6 years of tenure, ten-year retention rates increased for some age groups and fell for others. For workers with six or more years of tenure, however, a decrease in retention rates is observed for workers in their forties. Figure 5-D reveals that the increase in retention rates is statistically significant for workers aged 21 to 30 .

\section{Conclusion}

In our view, the general conclusion to emerge from our study is the approximate stability of aggregate job retention rates over the 1980s and early 1990s, in contrast to pronounced shifts in the wage distribution. However, disaggregation by current tenure, age, race, sex, education and occupation reveals some changes in four-year retention rates by demographic group that correspond loosely to changes in the wage structure. In particular, retention rates have declined for high school dropouts and high school graduates relative to college graduates, and for blacks relative to whites. However, except for the aggregate results for blacks, most of these changes are small and statistically insignificant.

Differences also emerge depending on the span examined. Using four-year spans in the 1980s and early 1990s, for example, we find evidence of slight decreases in job retention rates in certain segments of the U.S. labor market, and slight increases in others. Our preferred estimates indicate that the overall four-year retention rate decreased from .53 for 1983-1987 to .51 for 1987-1991. An analysis of ten-year retention rates for 1973-1983 and 1981-1991, however, indicates that longer-term job stability increased slightly in the 1980 s and early 1990 s 
relative to the 1970 s. Our preferred estimates indicate that the overall ten-year retention rate increased from .26 for $1973-1983$ to .27 for $1981-1991$.

Taken as a whole, the evidence to date certainly does not point toward a secular decline in job stability. However, there is some evidence of relative declines in job stability for those groups that experienced the sharpest relative wage declines over the sample period. It will be o! obvious interest to extend this analysis with future CPS tenure supplements. 


\section{References}

Abraham, Katherine G. (1990), "Restructuring the Employment Relationship: The Growth of Market-Mediated Work Arrangements," in Abraham and McKersie (eds.), New Developments in the Labor Market. Cambridge, MA: MIT Press.

Belous, Richard S. (1989), The Contingent Economy: The Growth of the Temporary, Part-Time, and Subcontracted Workforce, Washington, D.C.: National Planning Association.

Berman, Eli, John Bound, and Zvi Griliches (1993), "Changes in the Demand for Skilled Labor Within U.S. Manufacturing Industries: Evidence from the Annual Survey of Manufacturing," NBER Working Paper No. 4255.

Blackburn, McKinley L., David E. Bloom, and Richard B. Freeman (1990), "The Declining Economic Position of Less-Skilled American Men," in Burtless (ed.), A Future of Lousy Jobs? The Changing Structure of U.S. Wages. Washington, D.C.: Brookings Institution.

Bluestone, Barry and Bennett Harrison (1986), The Great American Job Machine: The Proliferation of Low-Wage Employment in the American Economy. Washington, D.C.: GPO. (1988), "The Growth of Low-Wage Employment, 1963-1986," American Economic Review Papers and Proceedings, 78, 124-128.

Bound, John and Richard B. Freeman (1992), "What Went Wrong? The Erosion of Relative Earnings and Employment Among Young Blacks in the 1980's," Quarterly Journal of Economics, 107, 201-32.

Bound, John and George Johnson (1989), "Changes in the Structure of Wages During the 1980s: An Evaluation of Altemative Explanations," American Economic Review, 82, 371-92.

Burtless, Gary (ed.) (1990), A Future of Lousy Jobs? The Changing Structure of U.S. Wages. Washington, D.C.: Brookings Institution.

Constantine, Jill M. and David Neumark (1994), "Did Changes in Training Contribute to the Growth of Wage Inequality in the 1980s?" NBER Working Paper No. 4729.

Farber, Henry S. (1993), "The Incidence of Job Loss: 1982-1991," Brookings Paper on Economic Activity: Microeconomics, 73-132.

Hall, Robert E. (1972), "Turnover in the Labor Force," Brookings Papers on Economic Activity, 3: $1972,709-756$.

(1982), "The Importance of Lifetime Jobs in the U.S. Economy," American Economic Review, 72, 716-724.

Katz, Lawrence F. and Kevin M. Murphy (1992), "Changes in Relative Wages, 1963-1987:

Supply and Demand Factors," Quarterly Journal of Economics, 107, 35-78. 
Light, Audrey and Manuelita Ureta (1992), "Panel Estimates of Male and Female Job Turnover Behavior: Can Female Nonquitters Be Identified?" Journal of Labor Economics, 10, 156181.

Marcotte, Dave E. (1993), "Has Job Stability Declined and Seniority Become Less Valuable?," Manuscript, School of Public Affairs, University of Maryland.

Mincer, Jacob (1991), "Job Training: Costs, Returns, and Wage Profiles," in D. Stern and J. M. Ritzen (eds.), Market Failure in Training? Berlin: Springer-Verlag.

Murphy, Kevin M. and Finis Welch (1992), "The Structure of Wages," Quarterly Journal of Economics, 107, 285-326.

Swinnerton, Kenneth and Howard Wial (1993), "Is Job Stability Declining in the U.S. Economy?," Discussion Paper \#42, U.S. Department of Labor.

Ureta, Manuelita (1992), "The Importance of Lifetime Jobs in the U.S. Economy, Revisited," American Economic Review, 82, 322-335.

Wellington, Alison J. (1993), "Changes in the Male/Female Wage Gap," Journal of Human Resources, 28, 383-411. 
</ref_section> 
TABLE 1

Retention Rate Spans and

Retention Rate Comparisons

Historical Retention Rate Spans

Estimable from CPS Tenure Supplements

$\begin{array}{lllll}1973 & 1978 & 1981 & 1983 & 1987\end{array}$

$\begin{array}{ccccc}5 & 3 & 2 * & 4 \# & 4 \# \\ 8 & 5^{*} & 6^{*} & 8 & \\ 10^{* \#} & 9^{*} & 10^{*} \# & & \\ 14^{*} & 13^{*} & & & \\ 18^{*} & & & & \end{array}$

Possible Retention Rate Comparisons

span: first year of span

Four-year: 1983\# 1987\#

Five-year: 1973 1978*

Eight-year: $1973 \quad 1983$

Ten-year: 1973*\# 1981*\#

*: Span crosses question types

\#: Comparison between spans not biased since question types are the same from one span to the next. 
TABLE 2

Retention Rates

over the four year spans

by current tenure group
Retention Rates:

Unadjusted

current tenure

group

$0-3$ years

0.43

span

$83+087 \quad 871091$

$3-6$ years

0.4

$6+$ years

$6-10$ years

$10+$ years

0.75
0.84
0.70

0.76

0.81

0.73

$0.57 \quad 0.56$

All years
Retention Rales:

Adjusted

for heaping

span

$831087 \quad 871091$

0.36

0.36

0.36

0.35

$0.57 \quad 0.48$

$0.69 \quad 0.70$

0.71

0.68

0.67

0.72

0.52

0.51

0.53

0.51

Note: Standard Errors are in the range of .002 to .005 . 
TABLE3

RETENTION RATES

Four-year Spans

By Education, Race and Sex

Four-year span
SUBGROUP

1983 to 1987

HS Grad or Drop Out College Grad

1987 to 1991

HS Grad or Drop Out College Grad

\section{$3106 \quad 6$ plus total}

$\begin{array}{llll}0.33 & 0.51 & 0.64 & 0.48\end{array}$

$\begin{array}{llll}0.39 & 0.67 & 0.74 & 0.58\end{array}$

$\begin{array}{llll}0.33 & 0.44 & 0.63 & 0.47\end{array}$

$\begin{array}{llll}0.40 & 0.56 & 0.81 & 0.59\end{array}$

\section{3 to 1987}

White

Black

1987 to 1991

White

Black

\section{3 to 1987}

Male

Female

1987 to 1991

Male

Female

1983 to 1987

All Workers

1987 to 1991

All Workers
0.35

0.41

0.35

0.35

0.36

0.36

0.35

0.36

0.36

0.36
0.56

0.59

0.68

0.77

0.49

0.46

0.69

0.76

0.51

0.53

Note: Standard Errors are in the range of .002 to .015 . 
TABLE 4

RETENTION RATES

Four-year Spans

By Industry and Occupation Subgroups

Four-year span

SUBGROUP

Current tenure group
0 te 3 to 6 plus

total

1983 to 1987

Goods-producing sector

Service-producing sector

1987 to 1991

Goods producing sector

Service producing sector

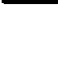

0.34

0.40

0.52

0.65

0.49

0.35

0.63

0.76

0.58

0.36

0.48

0.69

0.51

1983 to 1987

blue collar $1 /$

white collar and service workers $2 /$

0.36

0.49

0.71

0.52

1987 to 1991

blue collar $1 /$

white collar and service workers $2 /$

0.34

0.56

0.71

0.53

0.33

0.52

0.75

0.56

0.34

0.46

0.66

0.48

\section{3 to 1987}

professional $3 /$

sales and clerical 4/

service $5 /$

1987 to 1991

professional $3 /$

sales and clerical 4/

service $5 /$

$\begin{array}{llll}0.41 & 0.66 & 0.73 & 0.58 \\ 0.35 & 0.57 & 0.72 & 0.53 \\ 0.34 & 0.50 & 0.65 & 0.48 \\ & & & \\ 0.41 & 0.53 & 0.80 & 0.59 \\ 0.35 & 0.50 & 0.67 & 0.50 \\ 0.34 & 0.40 & 0.66 & 0.47 \\ & & & \\ 0.36 & 0.57 & 0.69 & 0.52 \\ & & & \\ 0.36 & 0.48 & 0.70 & 0.51\end{array}$

1983 to 1987

All Workers

1987 to 1991

All Workers

0.36

Note: Standard errors are in the range of .002 to .012

$1 /$ Precision production, repair, machine operators, assemblers, inspectors, transportation and material moving, handlers, and equipment cleaners.

2/ Managerial, professional, technical, sales, andministrative support, and service 3/ Managerial and professional

4/ Technical support, sales, and clerical

5/ Private houshold, protective service and other service 
TABLE 5

Retention Rates

over the ten year spans

by current tenure group

\begin{tabular}{|c|c|c|c|c|c|c|}
\hline \multirow{3}{*}{$\begin{array}{r}\text { current tenure } \\
\text { group }\end{array}$} & \multicolumn{2}{|c|}{$\begin{array}{c}\text { Retention Rates: } \\
\text { Unadjusted }\end{array}$} & \multicolumn{2}{|c|}{$\begin{array}{c}\text { Retention Rates: } \\
\text { Adjusted } \\
\text { for heaping }\end{array}$} & \multicolumn{2}{|c|}{$\begin{array}{l}\text { Retention Rates: } \\
\text { Adjusted } \\
\text { for heaping and } \\
\text { business cycle }\end{array}$} \\
\hline & \multicolumn{2}{|c|}{ span } & \multicolumn{2}{|c|}{ span } & \multicolumn{2}{|c|}{ span } \\
\hline & 731083 & 81 1091 & 73 10 83 & 81 to 91 & 23 to 83 & 81 to 91 \\
\hline $0-3$ years & 0.21 & 0.21 & 0.14 & 0.15 & 0.14 & 0.16 \\
\hline 3.6 years & 0.38 & 0.40 & 0.29 & 0.33 & 0.29 & 0.33 \\
\hline $6+$ years & 0.50 & 0.50 & 0.40 & 0.41 & 0.40 & 0.41 \\
\hline $6-10$ years & 0.43 & 0.47 & 0.38 & 0.46 & 0.38 & 0.47 \\
\hline $10+$ years & 0.50 & 0.51 & 0.41 & 0.38 & 0.41 & 0.39 \\
\hline All years & 0.34 & 0.34 & 0.26 & 0.27 & 0.26 & 0.27 \\
\hline
\end{tabular}

Note: Standard Errors are in the range of .002 to .005 . 
EIGURE I

Probablitty Distributions

Job Tenure Question

1973

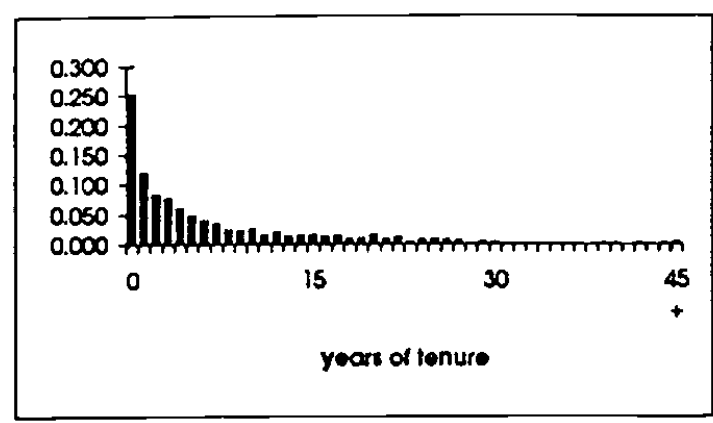

1978

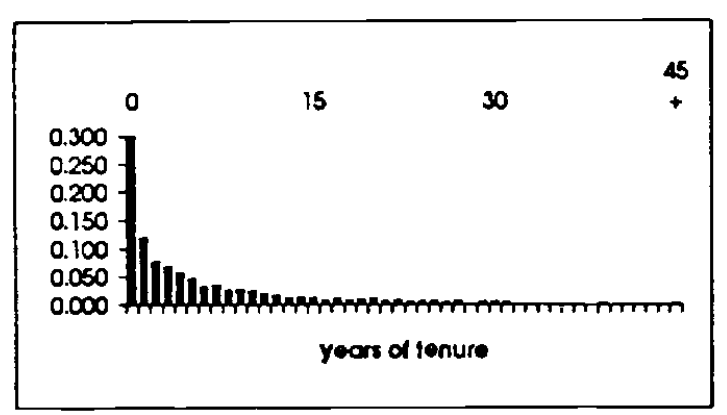

1981

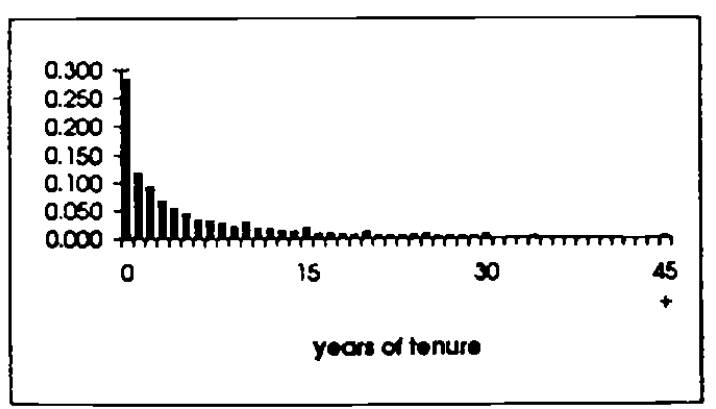

1983

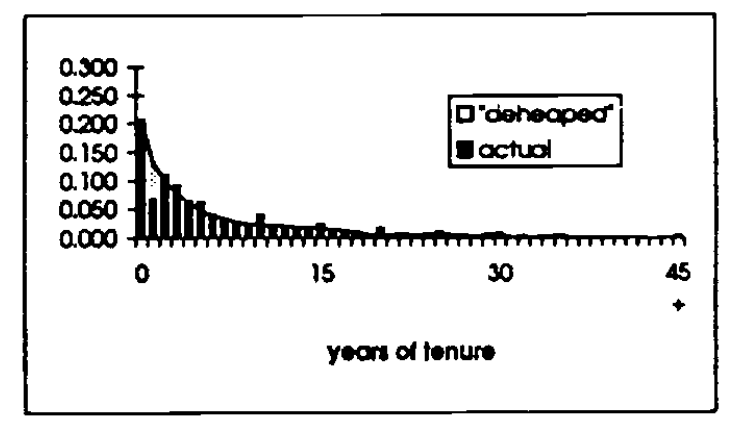

1987

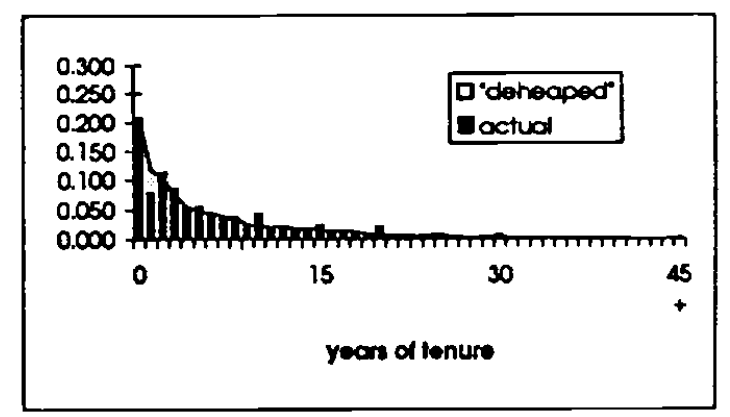

1991

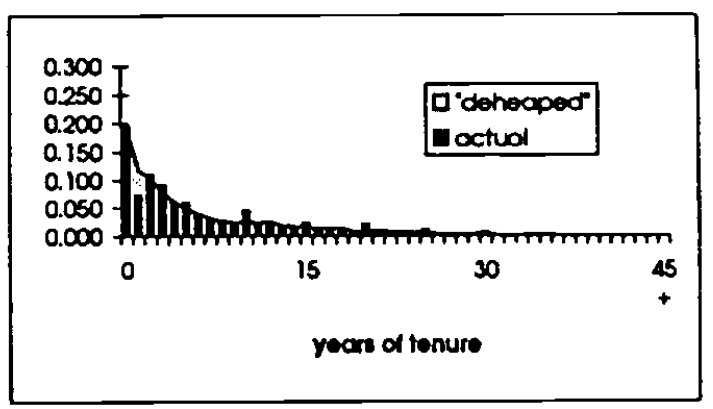

Note: "Deheaped" refers to the data adjusted for heoping and half year rounding. 
EIGURE 2-A

Four-yoor retention rates

by opo group

for current tenure of 0 - 3

(odjusted for neaping)

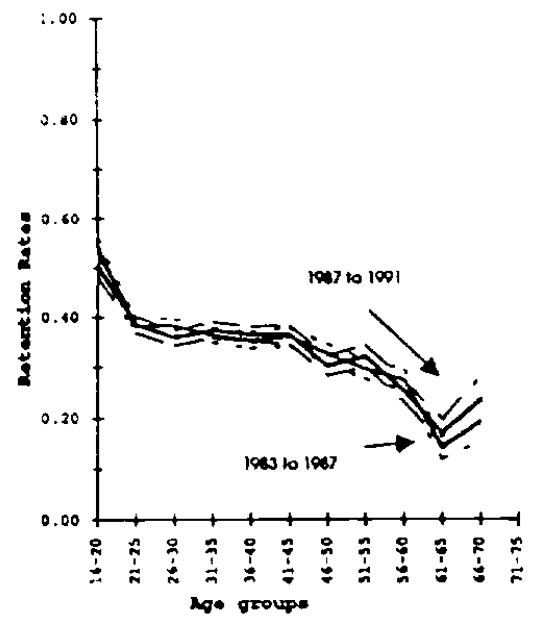

EUGURE $2-C$

Four-yeat retention rates

by oge group

for current tenure of 6 .

(adjusted tor heaping)

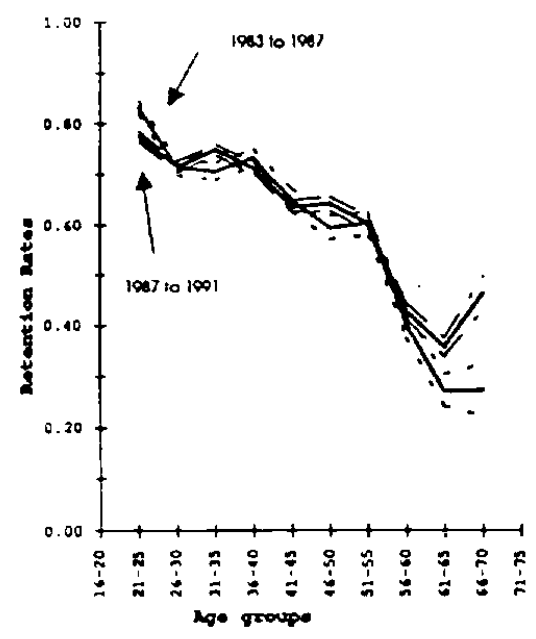

ELEUPE 2-1:

Four-yeau relention rates

by coo oroup

fox curent terure of 3 - 6

(adjusted for heapling)

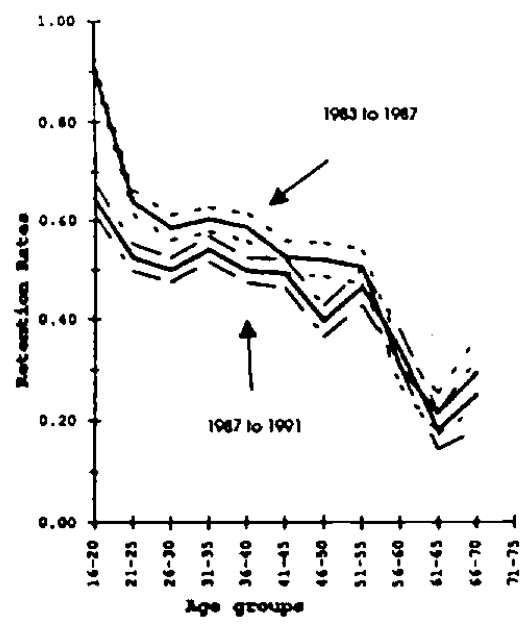

EIGURE 2-0

Four-yeat retention rates

by age group

for oll kevels of current tenure

(adjusted for heaping)

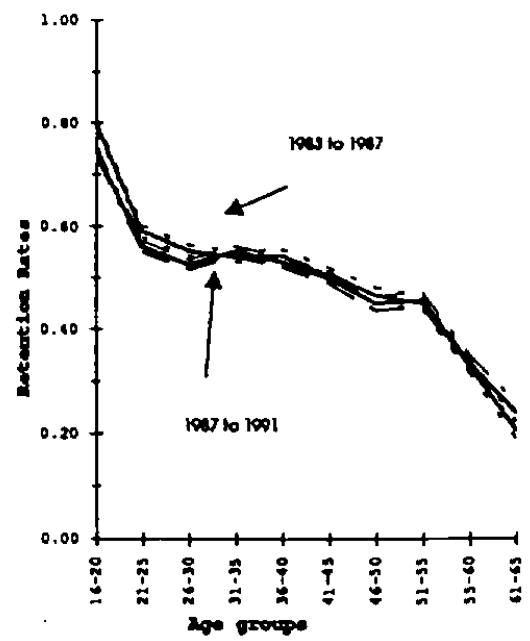

Note: Dotted lines represent confidence bands two standard devkations from solid line. 
EIGURE 3-S

Retention rate percent changes

between far-yeor spors

1983 to 1987 and 1987 to 1991

across educction levels -- by oge group

for current tenure 0.3 yeors

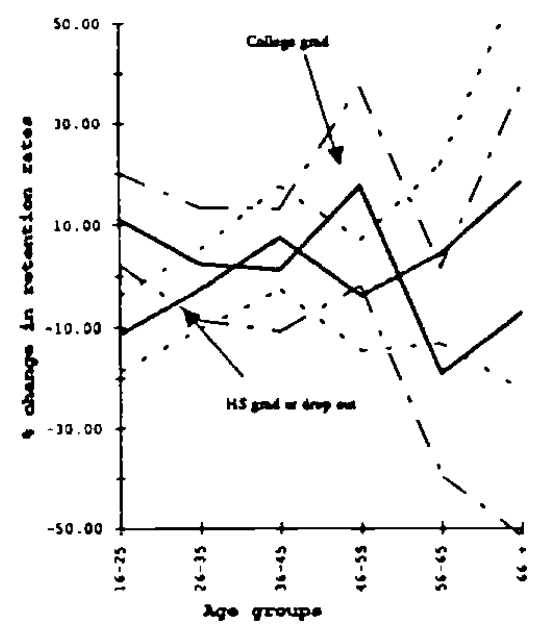

EGURE 3-C

Retention rate percent changes between four-year spons 1983 to 1987 and 1987 to 1991

across education levels -- by 00 group for current terure 6 phus years

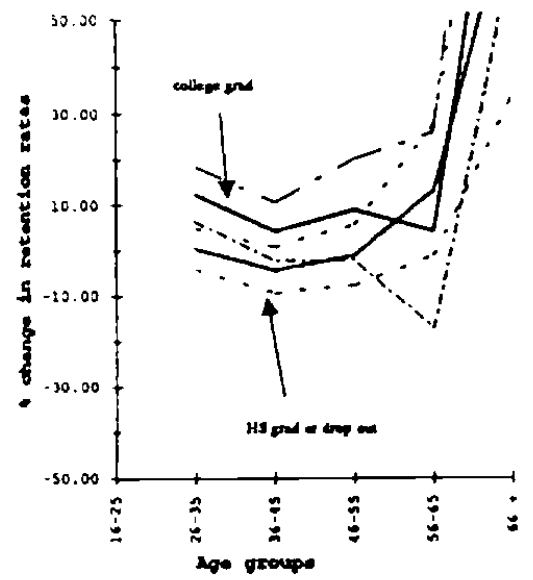

EIGURE 3-9

Relention rate percent changes

between four-yoar spons

1983 to 1987 and 1987 to 1991

ocross educotion levels - by age group for current tenure 3.6 yecrs

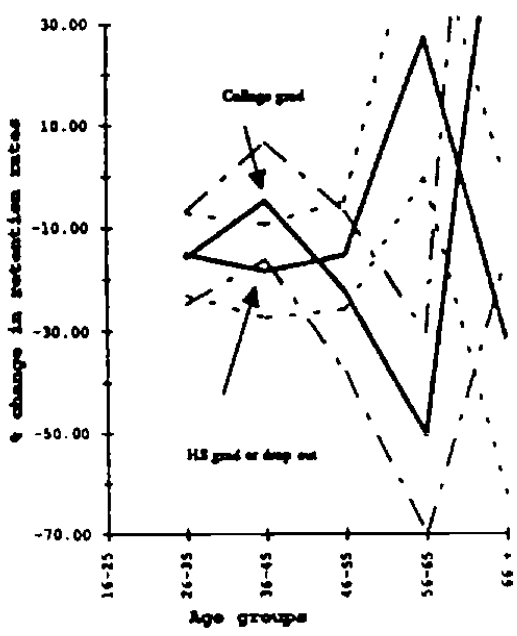

GGUPE 3-0

Retention rate percent changes

between far-year spons 1983 to 1987 and 1987 to 1991

ccross education levels - by coe group for all years of current ferure

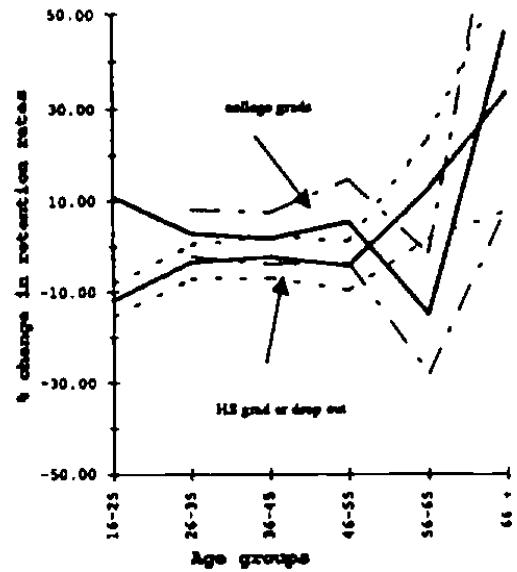

Note: Dotted Ines represent confidence bands two standard devations from solid ine. 
FlGURE 4-S

Retention rate percent changes between tour-yeor spons 1983 to 1987 and 1987 to 1901

across race -- by oge group for current tenure 0.3 years

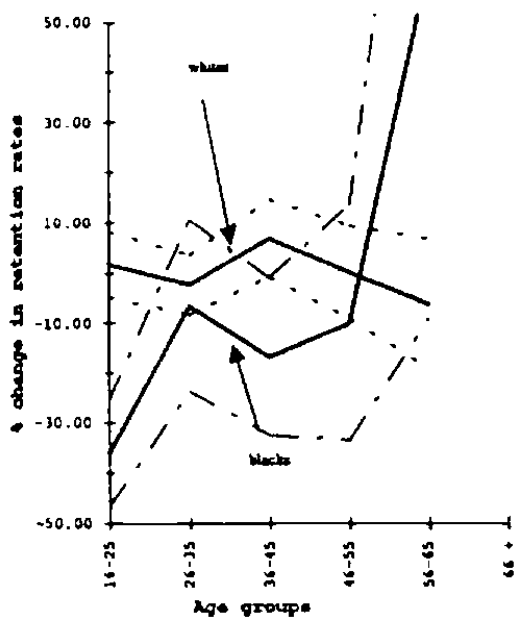

EKGURE 4-C

Retention rote pereent changer between four-yeor spons 1983 to 1987 and 1987 to 1991

across race-by age group for current tenure o plus years

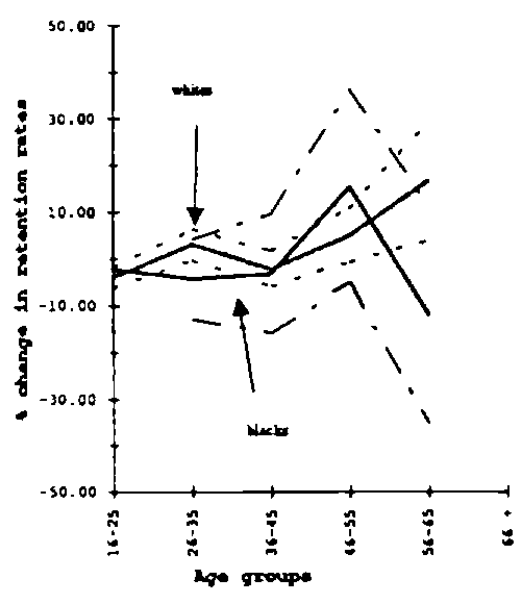

EREURE 1-B

Relention rate percent changes between four-year spore

1983 to 1987 and 1987 to 191

ocross roce - by ooe group for current tenure 3.6 years

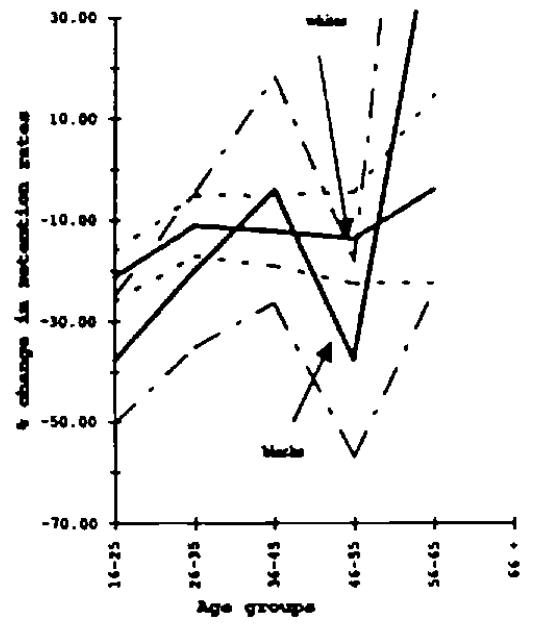

EIGURE A-D

Retention rote percent changes between four-yeat spans 1983 to 1987 and 1987 to 1991

ocross race - by age group for all years of curent tenure

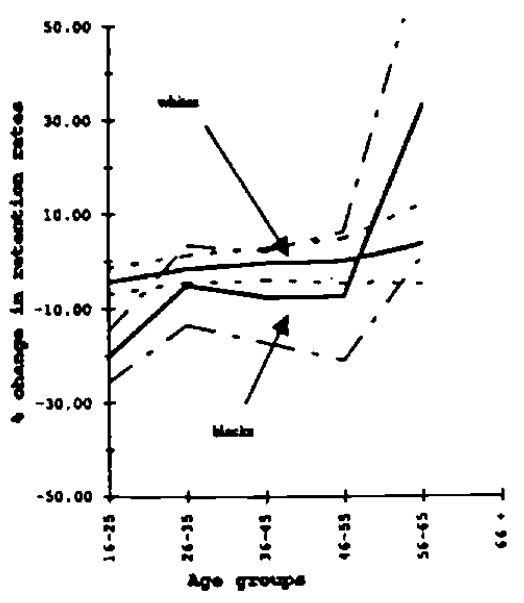

Note: Dotted lines represent confidence bands two standard devitions from solid ine. 
ElGURE 5 -A

Ten-yoar retention rotes

by oge group

for current tenure of 0 - 3

(odjusted for heaping)

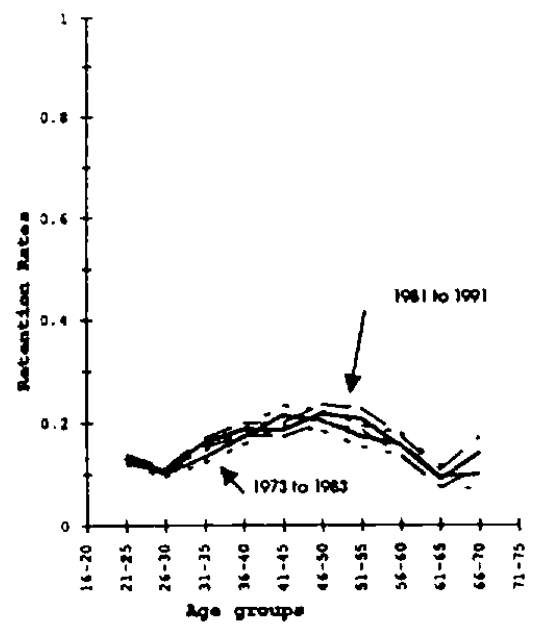

ELGURE 5 - 8

Ten-year rotention rotes

by oge group

for current tenure of 6 +

(adjusted for heaping)

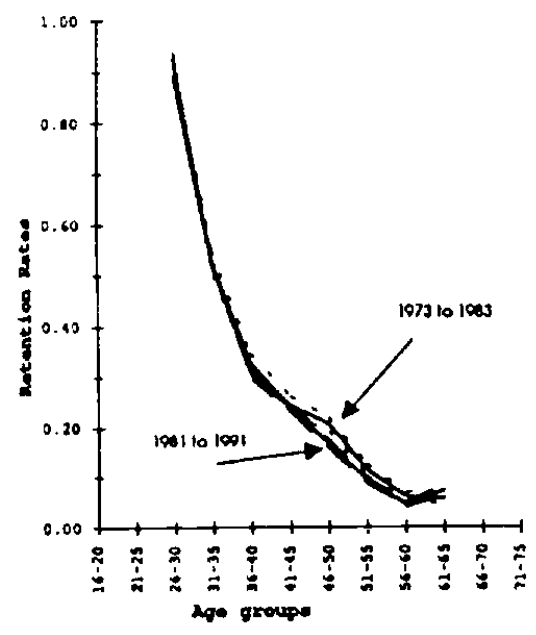

ElGURES-B

Ten-year retention rotes

by 000 group

for current tenure of 3.6

(adjuted for heaping)

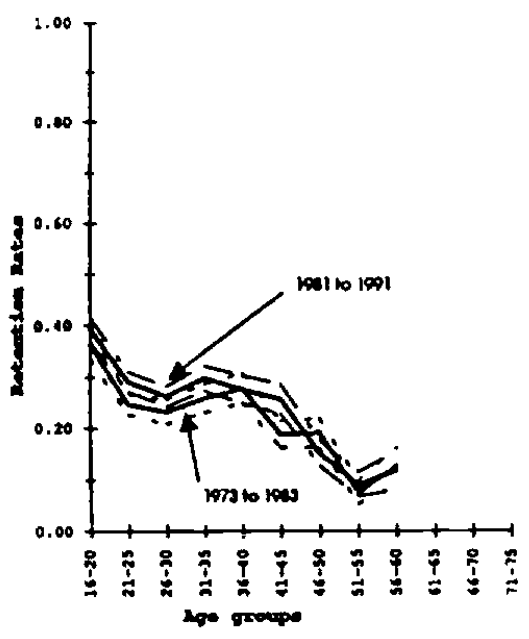

EIGURE 5-D

Ten-year retention rotes

by 000 croup

for all lovels of current temure (adjuted for heaping)

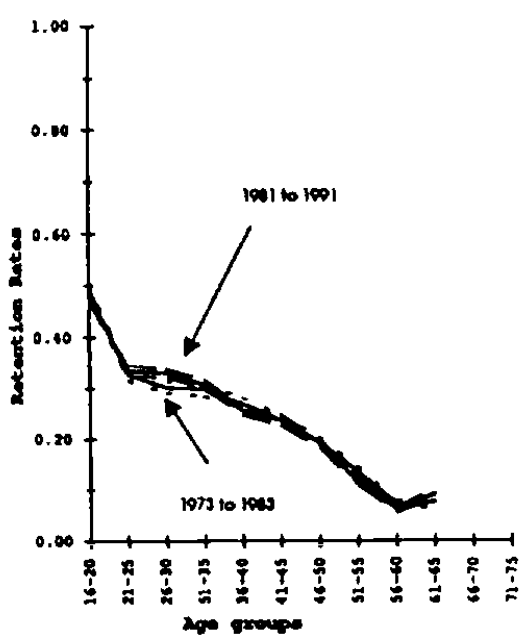

Note: Dotted lines represent confidence bands two standard deviations from solld line. 